J. Lake Sci. (湖泊科学), 2011, 23(4):657-664

http: //www.jlakes.org. E-mail : jlakes@niglas.ac.cn

(C) 2011 by Journal of Lake Sciences

\title{
巴丹吉林沙漠湖泊季节变化的遥感监测"
}

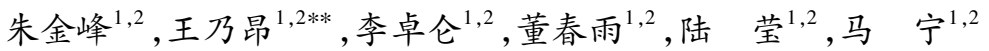 \\ ( 1 : 兰州大学资源环境学院,兰州 730000$)$ \\ ( 2 : 兰州大学干旱区水循环与水资源研究中心,兰州 730000$)$
}

摘 要: 利用 2001 年 12 月 28 日、 2002 年 3 月 18 日、 7 月 24 日、 9 月 26 日、 12 月 15 日五期 ETM ${ }^{+}$遥感影像, 提取了巴丹吉林 沙漠湖泊年内季节变化信息, 并分析了湖泊季节变化的统计特征与空间分布特征. 结果显示, 巴丹吉林沙漠湖泊总面积和数 量随季节更替呈现出明显的统计特征与空间分布特征. 湖泊总面积和数量在当年春、夏、秋、冬季均依次减少,到第二年春季 又逐渐恢复到前一年春季状态; 湖泊面积季节变化萎缩与增大区域呈集聚、连片分布态势, 部分时段湖泊面积变化表现出渐 变分布特征. 研究结果可为进一步深人研究巴丹吉林沙漠湖泊水循环、湖泊水量平衡、湖泊生态系统提供科学参考.

关键词: 巴丹吉林沙漠; 湖泊; 遥感;季节变化; 湖泊水循环

\section{RS-based monitoring seasonal changes of lake in Badain Jaran Desert}

ZHU Jinfeng ${ }^{1,2}$, WANG Naiang ${ }^{1,2}$, LI Zhuolun ${ }^{1,2}$, DONG Chunyu ${ }^{1,2}$, LU Ying $^{1,2} \&$ MA Ning ${ }^{1,2}$

(1: College of Earth and Environmental Science, Lanzhou University, Lanzhou 730000, P. R. China)

(2: Center for Hydrologic Cycle and Water Resources in Arid Region, Lanzhou Univesity, Lanzhou 730000, P. R. China)

Abstract: Using ETM ${ }^{+}$remote sensing images acquired on Dec. 28 in 2001, March 18, July 24, Sept. 26, Dec. 15 in 2002 , respectively, this study extracted the information of seasonal changes of the number and areas of lakes and analyzed the statistical characteristics and spatial distribution of them. The following conclusions were drawn. Firstly, the number and total area of desert lakes showed a decreasing trend from spring, summer, autumn to winter in the first year and regained the original condition gradually in the next spring. Secondly, the seasonal variation of lake area displayed an obvious characteristic that the atrophic and increased area of lake present a distribution of gathers and continual pieces and gradual changes in the spatial distribution showed in some time section. The automatic weather observation station of Badain Jaran Desert had been completed in winter in 2009. Our next focus is to study the scientific issues of lake water cycle further, water balance both using RS imagery data and meteorological observation data.

Keywords: Badain Jaran Desert; lake; remote sensing; seasonal changes; lake water cycle

在巴丹吉林沙漠高大沙丘之间的低地分布有许多内陆小湖泊 (海子), 总数约 144 个, 其中常年有水的 湖泊达 74 个, 主要集中分布在沙漠的东南部 ${ }^{[1]}$. 1990s 以来, 关于巴丹吉林沙漠湖泊水源、湖泊水循环等科 学问题一直是国内外学者研究的热点. 这些研究主要通过地球化学、地质外推等方法来解释湖泊成因、湖泊 水量在极度干旱的气候环境下为何长久不衰, 以及湖水的补给途径和补给来源等问题, 但得出的结论至今 说法不一 ${ }^{[2-12]}$. 遥感技术能够大范围、及时快速地获取地表环境信息, 为湖泊水域动态变化监测和相关参数 的反演研究带来了便利, 成为湖泊研究强有力的技术手段 ${ }^{[13]}$. 目前国内外学者在这些方面已经开展了大量 的研究工作, 并取得了很大进展 ${ }^{[14-22]}$. 但这些工作都围绕着研究区湖泊近几十年的动态变化及其原因展开 的, 而没有关注湖泊季节变化特征. 湖泊水域季节变化与降水、蒸发、地下水活动的季节性波动关系密切, 特 别是分布在西北干旱半干旱地区的内陆湖泊, 通过遥感监测分析其季节变化特征, 可为深人研究湖泊水循 环、湖泊水量平衡、湖泊生态系统提供科学参考. 本文基于以上思路, 利用 $\mathrm{ETM}^{+}$遥感影像, 提取巴丹吉林沙

* 国家基础科学人才培养基金项目 ( J0730536) 和高等学校博士学科点专项科研基金项目 (20090211110025) 联合资 助. 2010-07-06 收稿;2010-09-02 收修改稿. 朱金峰,男,1985 年生, 硕士研究生;E-mail : zhujf08@ lzu. cn.

** 通讯作者;E-mail:wangna@ lzu. edu. cn. 
漠湖泊年内季节变化信息,并分析湖泊季节变化的统计特征与空间分布特征.

\section{1 研究区概况}

巴丹吉林沙漠位于雅布赖盐湖与雅布赖山之西北, 宗乃山、省道 S218 公路之西, 黑河正义峡出山口、弱水 东岸至古日乃湖之东, 横跨 5 个经度, 东西长约 $442 \mathrm{~km}$; 合黎山、北大山、黑山头之北, 拐子湖、古居延泽之南, 纵 贯 3 个纬度, 南北宽约 $354 \mathrm{~km}$, 面积为 $5.2162 \times 10^{4} \mathrm{~km}^{2}$, 系我国仅次于塔克拉玛干沙漠的第二大沙漠 ${ }^{[23]}$. 区内 地势总体呈南高北低、东高西低的趋势, 海拔 $1000-1700 \mathrm{~m}$, 全年主要受 W-NW 大陆风系控制, 多年平均降水量 由东南向西北逐渐减少, 东南部约为 $120 \mathrm{~mm}$, 西北部不足 $40 \mathrm{~mm}$, 多年平均蒸发量大于 $3000 \mathrm{~mm}$, 年平均气温 $1-$ $8^{\circ} \mathrm{C}, 7$ 月份最高达 $37-41^{\circ} \mathrm{C}$, 沙面则高达 $70-80^{\circ} \mathrm{C}$, 气候极度干旱 ${ }^{[5]}$. 与世界上其他沙漠明显不同的是, 东南部 的高大复合型沙山, 相对高度一般达 $200-300 \mathrm{~m}$, 最高的超过 $430 \mathrm{~m}$; 沙山之间的洼地分布着许多大小不等的永 久性湖泊, 绝大多数属矿化度很高的盐碱湖, 还有一定数量的淡水湖, 这一奇特景观类型为世界罕见. 本文选 取沙漠东南部常年有水的湖泊区域 $\left(39^{\circ} 30^{\prime}-40^{\circ} 07^{\prime} \mathrm{N}, 101^{\circ} 42^{\prime}-102^{\circ} 40^{\prime} \mathrm{E}\right.$ ) (图 1) 作为研究区.

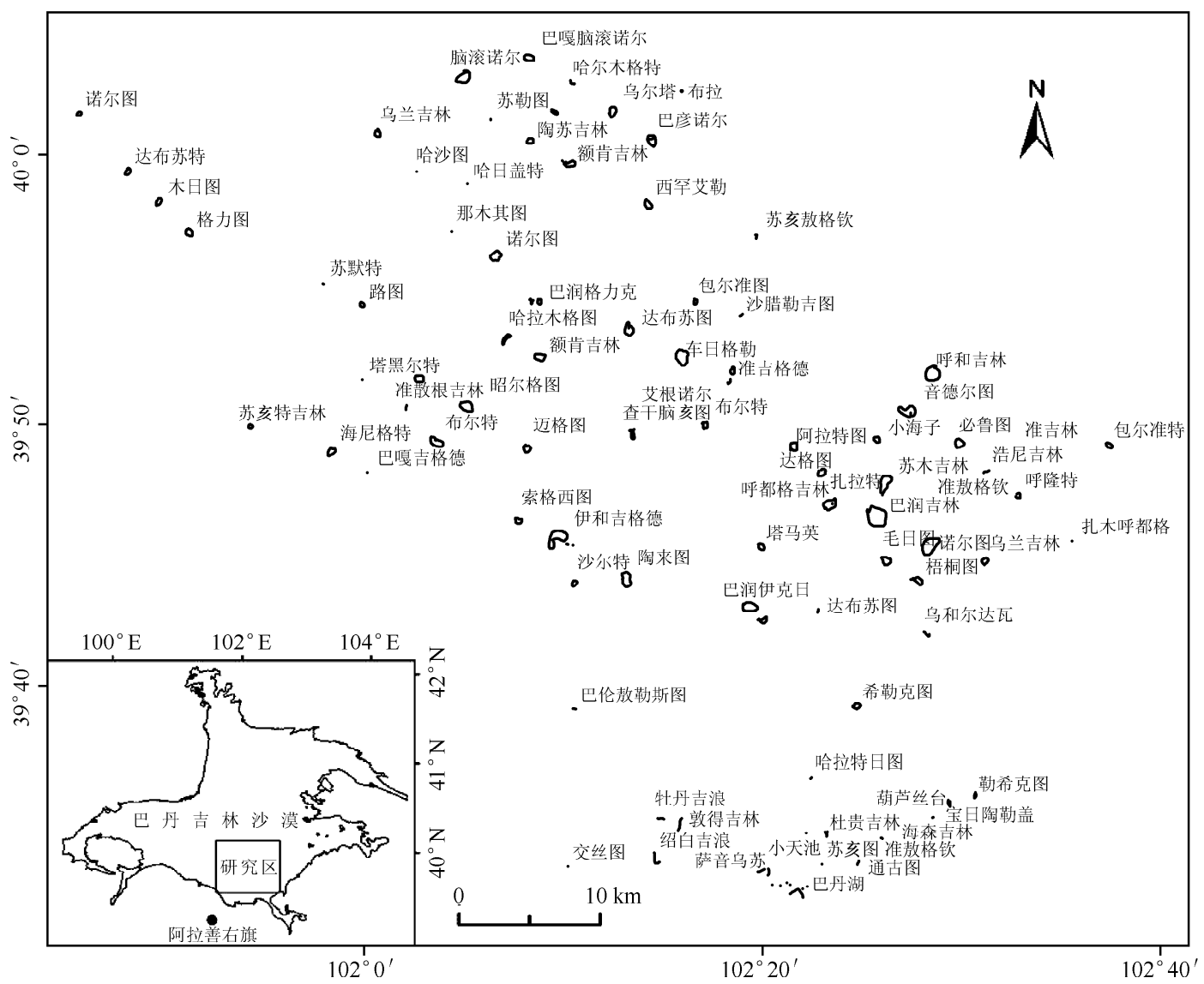

图 1 研究区位置及湖泊分布

Fig. 1 The location of study area and distribution of desert lakes

\section{2 数据与方法}

\section{1 数据源及其预处理}

研究所用的数据为全球陆地覆盖设施中心一一地球科学数据交换站点 (GLCF-ESDI) 提供的五期 Land- 
sat-7 ETM ${ }^{+}$L1T 级遥感影像, 轨道号 (Path/Row) 为 132/32、132/33, 时间分别为 2001 年 12 月 28 日、2002 年 3 月 18 日、 7 月 24 日、 9 月 26 日、 12 月 15 日,影像质量良好,平均云量均小于 $1 \%$,且已经过几何校正 ${ }^{[24]}$, 不 同月份数据间达到高精度配准. 根据研究区范围对影像进行拼接、裁剪. 采用 PCA 方法对 $\mathrm{ETM}^{+}$多光谱波段 与全色波段数据进行融合,此方法的融合效果在影像保光谱特性、信息量和清晰度三方面效果最佳 ${ }^{[25]}$, 融合 后数据的空间分辨率为 $15 \mathrm{~m}$. 采用 Albers 等积投影对影像进行投影转换. 影像的拼接、裁剪、融合、投影转换 均借助 ERDAS IMAGINE 9.2 图像处理软件完成.

\section{2 湖泊光谱特征分析}

相对于其他地物而言,湖泊水体对人射光具有 强吸收性,在大部分遥感传感器的波长范围内, 呈现 较弱的反射率. 清澈水体的遥感信息模型根据其反 射率可以近似表示为: 蓝光 $>$ 绿光 $>$ 红光 $>$ 近红 外 $>$ 短波红外 ${ }^{[26-29]}$. 从研究区湖泊、盐碱地、阴影、植 被、沙丘五种地物光谱曲线可以看出, 湖泊在蓝光波 段 $\left(\mathrm{ETM}^{+} 1\right.$ 波段) 的 $D N$ 值最大, 在近红外 $\left(\mathrm{ETM}^{+} 4\right.$ 波段)、短波红外 $\left(\mathrm{ETM}^{+} 5\right.$ 、7 波段) 同时具有强烈的 吸收性, 而其他四种地物的 $D N$ 值均高于湖泊, 特别 在 $\mathrm{ETM}^{+} 4 、 5 、 7$ 波段(图 2). 利用湖泊这种典型特 征,可建立提取湖泊信息的水体指数.

\section{3 湖泊信息提取}

2.3.1 湖泊信息提取约定为了真实反映湖泊数 量、面积大小随季节变化特征，在提取湖泊信息之 前,约定如下: (1) 湖泊指水域覆盖地区, 不包括湖泊

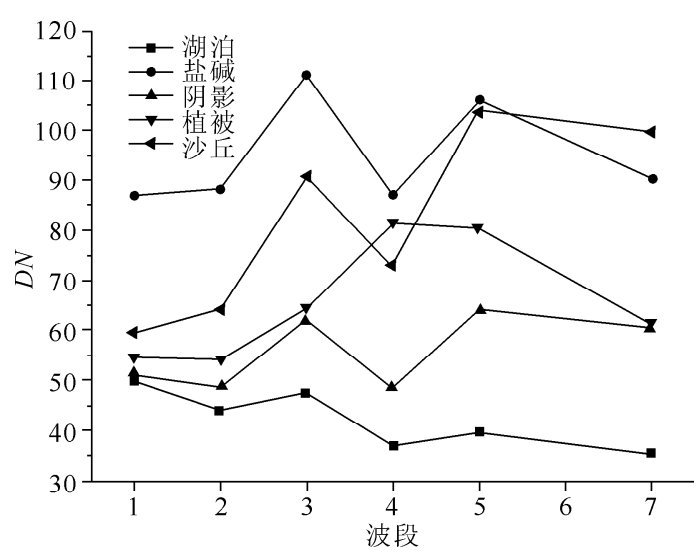

图 2 湖泊、盐碱地、阴影、植被、沙丘的光谱曲线

Fig. 2 Spectral curves of lakes, saline and alkaline land, shadow, vegetation and sand dune from Landsat-ETM ${ }^{+}$images 内的岛屿、湖泊周围沼泽化草甸、盐生草甸等植被、现代干涸盐碱湖盆等地区; (2) 野外考察和影像初步解译 均得出在冬季(2001 年 12 月 28 日、2002 年 12 月 15 日)影像上,部分湖面边缘水域出现结冰现象,在湖泊信 息提取时,这些结冰区域应当包括在湖泊之内; (3) 影像上大于等于 4 个像元 $\left(900 \mathrm{~m}^{2}\right)$ 的湖泊均提取出来; (4) 由于湖泊季节性萎缩, 部分湖泊出现分裂现象, 即一个大湖泊缩成几个小湖泊,在湖泊信息后处理时, 将 这几个小湖泊合并, 其面积和数量统一记为一个湖泊.

2.3.2 湖泊信息提取方法 前人已经建立了多个水体指数提取水体信息,如归一化水体指数 NDWI ( Normalized Difference Water Index ${ }^{[26]}$ 、改进归一化水体指数 MNDWI (Modified NDWI) ${ }^{[27]}$ 、增强型水体指数 $E W I$

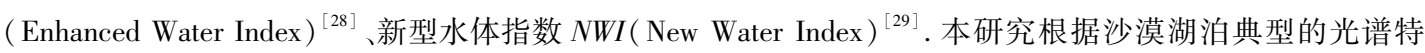
征,提出了一种用于提取沙漠湖泊信息的水体指数 DLWI, 其公式如下:

$$
D L W I=\frac{b_{\text {blue }}-b_{\text {mir }}}{b_{\text {blue }}-b_{\text {mir }}} \mathrm{C}
$$

其中: $b_{\text {blue }} b_{\text {mir }}$ 分别代表 $E T M^{+}$影像第 $1 、 5$ 波段的 $D N$ 值; C 为常数, 本研究取 100 , 目的是将 DLWI 的数值区 间进行拉伸,方便阈值的确定.

建立的 DLWI 指数可以轻易实现湖泊水体与其他地类的区分,这主要是由于: (1) 湖泊在第 1 波段具有 最大的 $D N$ 值,而在第 5 波段的 $D N$ 值很低（图 2)，由 $D L W I$ 指数得到的水体信息值均在正值区间; (2) 盐碱 地、阴影、植被和沙丘在第 5 波段的 $D N$ 值远远大于其各自在第 1 波段的 $D N$ 值, 由 $D L W I$ 指数得到的这 4 种 地物的信息值均在负值区间. 因此用阈值法就可达到正确提取湖泊信息的目的.

2.3 .3 湖泊信息后处理 对 DLWI 指数法提取的湖泊信息,依据“湖泊信息提取约定”进行人工处理. 对于 春、夏、秋三季对应的影像, 目视解译对湖泊边界进行修正,并去除小于 4 个像元的湖泊信息. 对于冬季对 


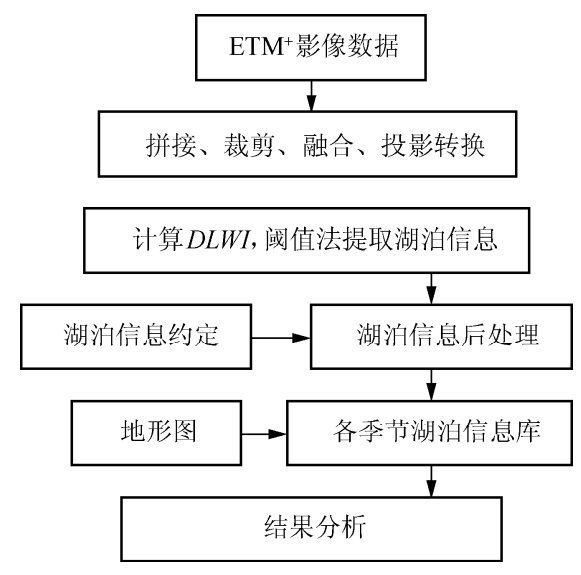

图 3 研究技术路线

Fig. 3 Completing routines for research

表 1 湖泊信息提取结果统计

Tab. 1 The statistical results of desert lakes interpreted from Landsat-ETM ${ }^{+}$images

\begin{tabular}{|c|c|c|c|c|c|c|}
\hline \multirow[b]{2}{*}{ 季节 } & \multicolumn{3}{|c|}{ 湖泊数量 } & \multicolumn{3}{|c|}{ 湖泊面积 } \\
\hline & $\begin{array}{l}\text { 总数量 } \\
\text { (个) }\end{array}$ & $\begin{array}{c}\text { 变化量 } \\
\text { (个) }\end{array}$ & $\begin{array}{c}\text { 变化率 } \\
(\%)\end{array}$ & $\begin{array}{l}\text { 总面积 } \\
\left(\mathrm{km}^{2}\right)\end{array}$ & $\begin{array}{l}\text { 变化量 } \\
\left(\mathrm{km}^{2}\right)\end{array}$ & $\begin{array}{c}\text { 变化率 } \\
(\%)\end{array}$ \\
\hline 2001年 冬季 & 84 & & & 16.98 & & \\
\hline 2002年 春季 & 109 & 25 & 29.76 & 19.16 & 2.18 & 12.84 \\
\hline 夏季 & 95 & -14 & -12.84 & 18.31 & -0.85 & -4.44 \\
\hline 秋季 & 87 & -8 & -8.42 & 16.87 & -1.44 & -7.86 \\
\hline 冬季 & 84 & -3 & -3.45 & 16.70 & -0.17 & -1.01 \\
\hline
\end{tabular}

应的影像, 存在两个问题并对其处理如下: (1) 由于成像时太阳高度角为一年中最小时 段, 高大沙山阴影与湖泊水体出现 “异物同 谱” 现象, 对提取后的信息目视去除所有沙 山阴影; (2) 由于冰面与湖泊水体光谱特征 存在差异, 去除沙山阴影后的湖泊信息没 有包含冰面,故目视补充解译冰面信息.

根据地形图信息为提取的湖泊空间数据 赋属性值, 最终形成研究区湖泊的春、夏、秋、 冬四季空间数据库. 总体研究技术路线如图 3 所示.

\section{3 结果与分析}

\section{1 湖泊季节变化统计特征}

利用 $\mathrm{ETM}^{+}$影像提取的研究区湖泊各季 节信息及变化情况可以看出, 巴丹吉林沙漠 湖泊总数量和总面积随季节更替均有所变 化, 春季湖泊总数量和总面积达到年内最大 值, 夏、秋、冬季湖泊总数量和总面积均逐渐减 小, 到了冬季湖泊总数量和总面积减小到年内 最小值. 从 2001 年冬季到 2002 年春季湖泊总 数量和总面积又开始增大, 重新达到年内最 大值(表 1).

依据研究区湖泊面积大小变化范围, 将 湖泊分为大于 $1 、 0.5-1 、 0.5 \mathrm{~km}^{2}$ 以下三种级 别, 分别称为 “大” “中”、“小” 湖泊, 其分级 信息如表 2 所示; 并将湖泊季节变化分级的 转化信息列出如表 3 所示, 进一步分析湖泊

季节变化的分级效应发现, “大”湖泊随季节更替的变化最明显, 湖泊总面积由春至冬依次递减, 春、夏、秋、 冬季分别为 $6.84 、 4.73 、 3.64 、 3.61 \mathrm{~km}^{2}$, 其中, 春夏之交 2 个“大”湖泊萎缩成“中”湖泊, 夏秋之交 1 个“大” 湖泊萎缩成“中”湖泊, 而由冬至春, 有 3 个“中”湖泊增大成“大”湖泊, 补给了湖泊面积; “中”湖泊随季节 更替的变化也比较明显, 湖泊面积春、夏、秋、冬季分别为 $1.69 、 3.16 、 4.03 、 3.85 \mathrm{~km}^{2}$, 呈先增大后减小的变 化趋势, 这主要是由于在春夏之交和夏秋之交个别“大” 湖泊萎缩成“中”湖泊形成对 “中” 湖泊面积的补 给, 由冬至春 3 个“中”湖泊又增大成“大”湖泊, 致使“中”湖泊面积有所减小; “小”湖泊随季节更替的 面积变化相对不太明显, 但湖泊数量变化由春至冬呈明显的减少特征, 春、夏、秋、冬季分别为 $100 、 87$ 、 $79 、 76$ 个, 排除春夏之交 1 个“中”湖泊萎缩成“小”湖泊对“小”湖泊数量的补给后可看出, 春夏之交、 夏秋之交、秋冬之交干涸的湖泊数量分别为 $14 、 7 、 3$ 个, 而由冬至春 25 个“小”湖泊再现水域, 补给了 湖泊面积.

由此可知, 湖泊总面积和数量随季节更替均有较大变化, 当年春、夏、秋、冬季湖泊总面积和数量均依次 减少, 到第二年春季, 湖泊总面积和数量又逐渐恢复到前一年状态; 由于湖泊面积的季节变化性, “大”、 “中”、小”湖泊之间存在相互转化特点, 部分“小”湖泊表现出“干涸”与“再现水域” 的变化现象, 这些变化 均表现在湖泊总面积与数量季节总体变化特征的过程中. 
表 2 湖泊分级信息

Tab. 2 The classified information of desert lakes

\begin{tabular}{|c|c|c|c|c|c|c|c|}
\hline \multirow{2}{*}{\multicolumn{2}{|c|}{ 季节 }} & \multicolumn{2}{|c|}{ 大于 $1 \mathrm{~km}^{2}$ 的湖泊 } & \multicolumn{2}{|c|}{$0.5-1 \mathrm{~km}^{2}$ 的湖泊 } & \multicolumn{2}{|c|}{ 小于 $0.5 \mathrm{~km}^{2}$ 的湖泊 } \\
\hline & & 总数量 $($ 个) & 总面积 $\left(\mathrm{km}^{2}\right)$ & 总数量 (个) & 总面积 $\left(\mathrm{km}^{2}\right)$ & 总数量 $($ 个) & 总面积 $\left(\mathrm{km}^{2}\right)$ \\
\hline 2001 年 & 冬季 & 3 & 3.61 & 6 & 4.53 & 75 & 8.84 \\
\hline \multirow[t]{4}{*}{2002 年 } & 春季 & 6 & 6.84 & 3 & 1.69 & 100 & 10.63 \\
\hline & 夏季 & 4 & 4.73 & 4 & 3.16 & 87 & 10.41 \\
\hline & 秋季 & 3 & 3.64 & 5 & 4.03 & 79 & 9.19 \\
\hline & 冬季 & 3 & 3.61 & 5 & 3.85 & 76 & 9.24 \\
\hline
\end{tabular}

表 3 湖泊季节变化分级转化信息

Tab. 3 The transformation of classified information of desert lakes

\begin{tabular}{|c|c|c|c|c|c|c|c|}
\hline & \multirow{2}{*}{ 分级转化信息 } & \multicolumn{2}{|c|}{ 大于 $1 \mathrm{~km}^{2}$ 的湖泊 } & \multicolumn{2}{|c|}{$0.5-1 \mathrm{~km}^{2}$ 的湖泊 } & \multicolumn{2}{|c|}{ 小于 $0.5 \mathrm{~km}^{2}$ 的湖泊 } \\
\hline & & 数量 $($ 个) & 总面积 $\left(\mathrm{km}^{2}\right)$ & 数量 $($ 个) & 总面积 $\left(\mathrm{km}^{2}\right)$ & 数量(个) & 总面积 $\left(\mathrm{km}^{2}\right)$ \\
\hline \multirow{3}{*}{ 冬-春 } & 大于 $1 \mathrm{~km}^{2}$ 的湖泊 & 3 & 3.76 & 3 & 3.08 & - & - \\
\hline & $0.5-1 \mathrm{~km}^{2}$ 的湖泊 & - & - & 3 & 1.69 & - & - \\
\hline & 小于 $0.5 \mathrm{~km}^{2}$ 的湖泊 & - & - & - & - & 75 & 10.27 \\
\hline \multirow[t]{3}{*}{ 春-夏 } & 大于 $1 \mathrm{~km}^{2}$ 的湖泊 & 4 & 4.73 & - & - & - & - \\
\hline & $0.5-1 \mathrm{~km}^{2}$ 的湖泊 & 2 & 1.97 & 2 & 1.19 & - & - \\
\hline & 小于 $0.5 \mathrm{~km}^{2}$ 的湖泊 & - & - & 1 & 0.49 & 86 & 9.92 \\
\hline \multirow[t]{3}{*}{ 夏一秋 } & 大于 $1 \mathrm{~km}^{2}$ 的湖泊 & 3 & 3.64 & - & - & - & - \\
\hline & $0.5-1 \mathrm{~km}^{2}$ 的湖泊 & 1 & 0.99 & 4 & 3.04 & - & - \\
\hline & 小于 $0.5 \mathrm{~km}^{2}$ 的湖泊 & - & - & - & - & 79 & 9.19 \\
\hline \multirow[t]{3}{*}{ 秋-冬 } & 大于 $1 \mathrm{~km}^{2}$ 的湖泊 & 3 & 3.61 & - & - & - & - \\
\hline & $0.5-1 \mathrm{~km}^{2}$ 的湖泊 & - & - & 5 & 3.85 & - & - \\
\hline & 小于 $0.5 \mathrm{~km}^{2}$ 的湖泊 & - & - & - & - & 76 & 9.24 \\
\hline
\end{tabular}

\section{2 湖泊季节变化空间分布特征}

为了分析湖泊季节变化空间分布特征,利用 ArcGIS 9.2 软件对各季节湖泊空间数据进行叠加分析, 得 到各季节湖泊面积变化量,处理如下: (1) 根据空间矢量数据分级符号化方法 ${ }^{[30]}$, 按照 Natural Breaks 方案对 湖泊面积季节变化量进行分级符号化处理,得到其点层上的空间分布格局; 2 基于 GIS 的空间插值方法,在 采用交叉验证法对反距离加权法 (Inverse Distance Weighting, IDW)、普通克里格法 (Ordinary Kriging，OK)、

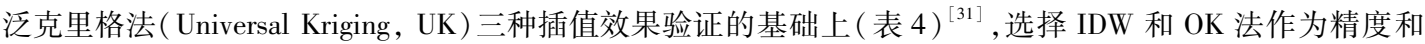
效果最优的方法,分别对夏一秋、秋-冬和冬-春、春-夏湖泊面积季节变化量进行插值模拟,得到其面层上的 空间分布格局 (图 4). 现结合图 1 和图 4,对湖泊季节变化空间分布特征解释如下:

(1) 由春至夏,研究区西北部格力图、达 布苏图和中北部包尔准图、准吉格德周围形 成两大湖泊萎缩区域,梧桐图、诺尔图到音德 尔图一带也是湖泊萎缩较大的区域,萎缩的 湖泊共计 66 个,其中位于两大湖泊萎缩区域 中干涸的季节性湖泊达到 7 个; 与此同时,东 南部宝日陶勒盖、准敖格钦一带的淡水湖形 成湖泊增大区域,其他地区亦有个别增大湖 泊呈零星分布, 增大的湖泊共计 43 个. 在总 体空间趋势上, 从研究区西北部到东南部, 湖 泊面积变化表现出萎缩-基本不变-增大的渐 变分布特征.
表 4 三种空间插值方法的交叉验证结果

Tab. 4 Cross-validation results of the three spatial interpolation methods

\begin{tabular}{llllll}
\hline \multirow{2}{*}{ 空间插值方法 } & \multicolumn{4}{c}{ 湖泊面积季节变化量 $\left(\mathrm{hm}^{2}\right)$} \\
\cline { 3 - 6 } & & 冬-春 & 春一夏 & 夏一秋 & 秋-冬 \\
\hline \multirow{2}{*}{ IDW } & $M A E$ & 0.0145 & 0.1155 & 0.0208 & 0.0129 \\
& $R M S E$ & 2.4370 & 2.2020 & 2.3980 & 2.8300 \\
\multirow{2}{*}{ OK } & $M A E$ & 0.0043 & 0.0015 & 0.0483 & 0.0351 \\
& RMSE & 2.4360 & 2.1090 & 2.4500 & 2.8770 \\
\multirow{2}{*}{$\mathrm{UK}$} & $M A E$ & 0.0826 & 0.0450 & 0.1681 & 0.0236 \\
& RMSE & 2.4510 & 2.1810 & 2.5320 & 2.9160 \\
\hline
\end{tabular}



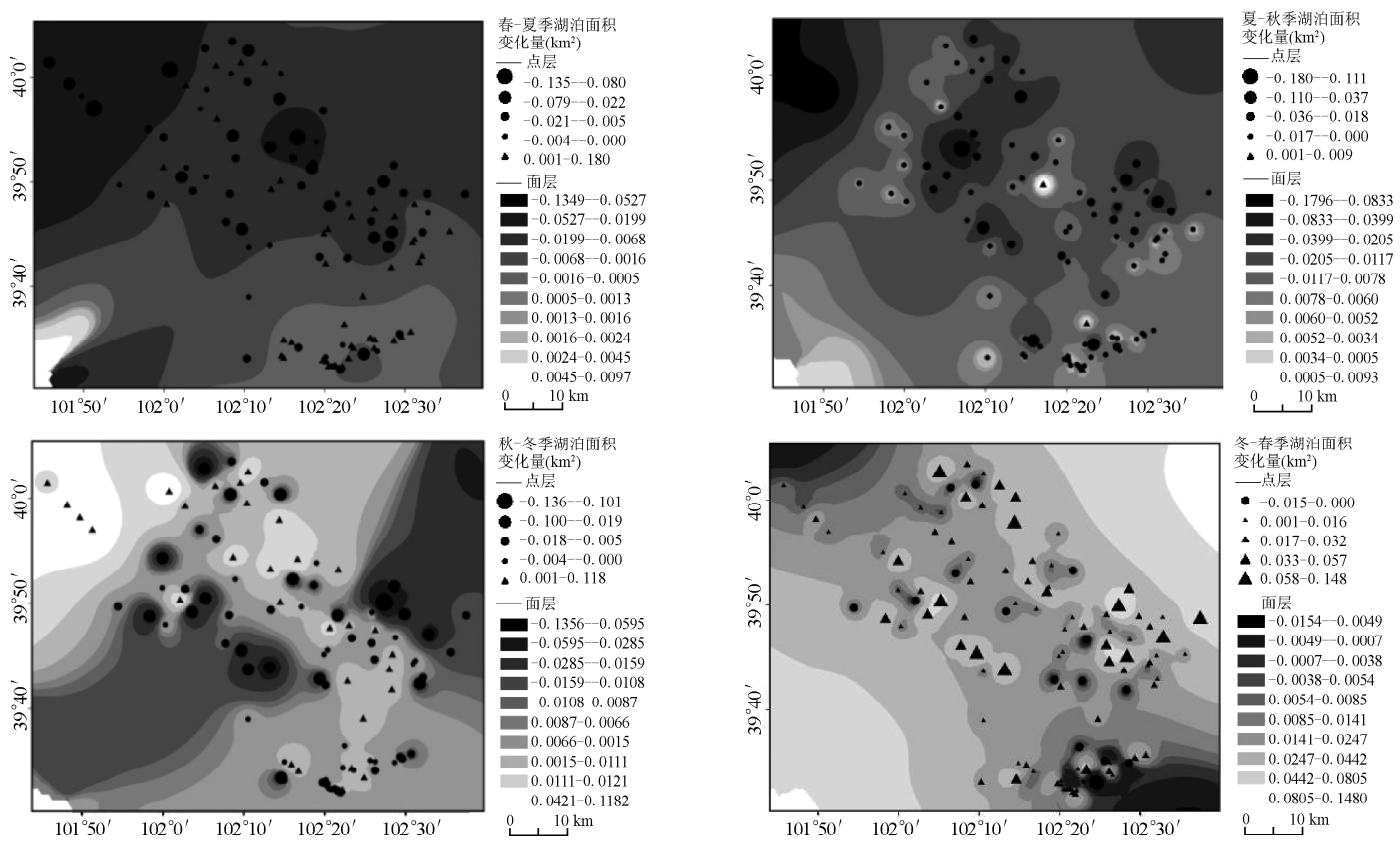

冬一春季湖泊面积 变化量 $\left(\mathrm{km}^{2}\right)$ 一点层 - $0.001-0.016$ 0. $017-0.032$ \ $0.058-0.148$ 面层 -0.004y- $-0.000 /$ $-0.0038-0.0054$
$0.0051-0.0085$ $0.0051-0.0085$
$0.0085-0.0141$ $0.0141-0.0247$ - $0.0247-0.0442$ $0.0442-0.0805$
$0.0805-0.1480$ $10 \mathrm{~km}$

图 4 湖泊面积季节变化量空间分布格局

Fig. 4 Spatial pattern of the lake area seasonal variation

(2) 由夏至秋, 研究区西北部木日图和哈拉木格图形成两大湖泊萎缩区域, 音德尔图、浩尼吉林一带也 是湖泊萎缩较大的区域, 萎缩的湖泊共计 92 个, 其中位于两大湖泊萎缩区域中干涸的季节性湖泊有 2 个; 期 间,增大的湖泊只有 3 个, 分别是位于中部的布尔特和东南部的哈拉特日图、巴丹湖. 与春夏之交相比,此期 间萎缩的湖泊数量大大增加. 在总体上湖泊面积变化趋势虽不明显, 但仍可以看出从西北到东南湖泊萎缩 量逐渐减少的变化特征.

(3) 由秋至冬, 研究区中东部音德尔图、呼隆特和西南部陶来图、昭尔格图一带形成两大湖泊萎缩区 域, 北部脑滚诺尔、陶苏吉林周围也是湖泊萎缩较大的区域, 萎缩的湖泊共计 68 个, 其中干涸的季节性湖泊 共计 15 个; 西北部达布苏图、乌兰吉林和东南部希勒克、通古图一带形成湖泊增大区域, 增大的湖泊共计 31 个,其中再现水域的季节性湖泊共计 12 个. 与春夏之交、夏秋之交相比, 此期间湖泊面积变化总体空间趋势 很明显, 增大的湖泊在西北一东南方向上形成一带状区域, 而在此带状区域的中部两边则为湖泊萎缩区域.

(4) 由冬至春, 研究区中东部音德尔图、诺尔图和西南部布尔特、伊和吉格德周围形成两大湖泊增大区 域, 北部的脑滚诺尔、南部的杜贵吉林一带也是湖泊增大较大的区域, 增大的湖泊共计 96 个, 其中再现水域 的季节性湖泊达到 25 个; 期间亦有个别面积减小的湖泊, 如北部的苏勒图、南部的哈拉特日图等. 此期间是 湖泊总面积与数量补给的时间段, 湖泊面积变化表现出总体增大的空间分布格局, 只在南部淡水湖区域出 现较小萎缩区域.

从以上分析看出, 湖泊面积季节变化在空间分布上特征明显, 湖泊萎缩与增大的区域呈集聚、连片分布 态势, 部分时段湖泊面积变化表现出渐变分布特征.

\section{4 结论}

利用 $\mathrm{ETM}^{+}$遥感影像提取了巴丹吉林沙漠湖泊年内季节变化信息, 从统计结果和空间分布两方面分析 了湖泊季节变化特征, 得出以下结论: (1) 巴丹吉林沙漠湖泊总面积和数量在当年春、夏、秋、冬季均依次减 少, 到第二年春季湖泊总面积和数量又逐渐恢复到前一年状态, 在此变化过程中伴有 “大”、“中”、“”湖泊 
之间的相互转化以及部分“小”湖泊“干涸”和“再现水域”的现象特征. (2) 在空间分布上,巴丹吉林沙漠湖 泊面积季节变化特征明显,湖泊萎缩与增大区域呈集聚、连片分布态势, 部分时段湖泊面积变化表现出渐变 分布特征.

由于缺少 2002 年 6 月 $\mathrm{ETM}^{+}$数据, 本文在遥感影像获取时间与季节变化对应问题上尚存缺陷. 本研究 组已于 2009 年末建成巴丹吉林沙漠野外观测实验站. 利用全年 12 月份遥感数据逐月监测沙漠湖泊变化,将 其结果与沙漠实验站观测资料对比分析,进一步解释巴丹吉林沙漠湖泊年内季节变化的原因、湖泊水循环、 湖泊水量平衡等科学问题,是下一步研究的重点.

致谢: 本文在写作和修改过程中得到兰州大学地球系统科学研究所张建明副教授、黄银洲博士、李育博士等 的帮助,两位审稿专家对本文修改也提出了重要建议,在此一并感谢.

\section{5 参考文献}

［1］朱震达,吴 正,刘 恕等. 中国沙漠概论. 北京:科学出版社, 1980:73-76.

[ 2 ] Yang XP, Martin AJW. The ion chemistry of lakes and late Holocene desiccation in the Badain Jaran Desert, Inner Mongolia, China. Catena, 2003, 51(1) : 45-60.

[ 3 ] Yang XP. Chemistry and late Quaternary evolution of ground and surface waters in the area of Yabulai Mountains, western Inner Mongolia, China. Catena, 2006, 66(1-2): 135-144.

[ 4 ] 杨小平. 巴丹吉林沙漠腹地湖泊的水化学特征及其全新世以来的演变. 第四纪研究, 2002,22(2): 97-104.

[5] 马妮娜, 杨小平. 巴丹吉林沙漠及其东南边缘地区水化学和环境同位素特征及其水文学意义. 第四纪研究, 2008, 28 (4): $: 702-711$.

[6]马金珠,陈发虎,赵 华. 1000 年以来巴丹吉林沙漠地下水补给与气候变化的包气带地球化学记录. 科学通报, $2004,49(1): 22-26$.

[ 7 ] 马金珠,黄天明,丁贞玉等. 同位素指示的巴丹吉林沙漠南缘地下水补给来源. 地球科学进展, 2007,22 (9): 922-930.

[ 8 ] Gates JB, Edmunds WM, Darling WG et al. Conceptual model of recharge to southeastern Badain Jaran Desert groundwater and lakes from environmental tracers. Applied Geochemistry, 2008, 23(12) : 3519-3534.

[ 9 ] 陈建生, 赵 霞, 盛雪芬等. 巴丹吉林沙漠湖泊群与沙山形成机理研究. 科学通报, 2006,51(23):2789-2796.

[10］陈建生,凡哲超,汪集旸等. 巴丹吉林沙漠湖泊及其下游地下水同位素分析. 地球学报, 2003, 24 (6) : 497-504.

[11] 赵 霞,陈建生. 相似优先比法研究巴丹吉林沙漠及周边地区地下水补给. 湖泊科学, 2006,18 (4): 407-413.

[12] Chen JS, Li L, Wang JY et al. Water resources: Groundwater maintains dune landscape. Nature, 2004, 432 : 459-460.

[13］王海波,马明国. 基于遥感的湖泊水域动态变化监测研究进展. 遥感技术与应用,2009,24 (5):674-684.

[14] Zhao SQ, Fang JY, Miao SL et al. The 7-decade degradation of a large freshwater lake in central Yangtze river, China. Environmental Science and Technology, 2005, 39: 431-436.

１5］殷立琼,江 南,杨英宝. 基于遥感技术的太湖近 15 年面积动态变化. 湖泊科学,2005,17(2):139-142.

[16］鲁安新,王丽红,姚檀栋. 青藏高原湖泊现代变化遥感方法研究. 遥感技术与应用,2006,21(3):173-177.

[17］马国明,宋 怡, 王雪梅. 1973-2006 年新疆若㒸湖泊群遥感动态监测研究. 冰川冻土, 2008,30(2): 189-195.

[18］牛沂芳,李才兴, 习晓环等. 卫星遥感检测高原湖泊水面变化及与气候变化分析. 干旱区地理, 2008, 31 (2): 284-290.

[19］王丽红,赵 杰,鲁安新等. 基于遥感的西藏 S301 公路沿线湖泊变化研究. 遥感技术与应用,2008,23(6):658-661.

[20］贾珅玥,肖鹏峰. 基于多时相图谱的青藏高原湖泊变化检测研究. 国土资源遥感, 2009,82:78-85.

[21］李晶晶,贾建华,郝景研. 基于 RS 的松嫩平原大安湖泊群面积提取与动态变化分析. 遥感信息,2009,(3):44-48.

[22] 熊 波,陈学华,宋孟强等. 基于 RS 和 GIS 的沙漠湖泊动态变化研究一一巴丹吉林沙漠为例. 干旱区资源与环 境, 2009, 23(8): $: 91-98$.

[23] 朱金峰,王乃昂,陈红宝等. 基于遥感的巴丹吉林沙漠范围与面积分析. 地理科学进展, 2010,29(9): 1087-1094.

[24] Williams D. Landsat7 Science Data Users Handbook[EB/OL]. http: //landsathandbook. gsfc. nasa. gov/handbook. html.

[25] 杨丽萍,夏敦胜,陈发虎. Landsat7 ETM ${ }^{+}$全色与多光谱数据融合算法的比较. 兰州大学学报 (自然科学版), 2007, $\mathbf{4 3}(4): 7-11$.

[26] McFeeters SK. The use of normalized difference water index (NDWI) in the delineation of open water features. Internation- 
al Journal of Remote Sensing, 1996, 17(7) : 1425-1432.

[27] 徐涵秋. 利用改进的归一化差异水体指数 (MNDWI) 提取水体信息的研究. 遥感学报,2005,9(5):589-595.

[28] 问 霈, 张友静, 张 元. 利用增强型水体指数 (EWI) 和 GIS 去噪音技术提取半干旱地区水体信息的研究. 遥感信 息 ,2007,6 :62-67.

[29］丁 凤. 一种基于遥感数据快速提取水体信息的新方法. 遥感技术与应用,2009,24(2):167-171.

[30] 汤国安,杨 昕. ArcGIS 地理信息系统空间分析实验教程. 北京:科学出版社,2006:125-134.

[31] 林忠辉,莫兴国,李宏轩等. 中国陆地区域气象要素的空间插值. 地理学报,2002,57(1):47-54. 